\title{
Metastatic Extraskeletal Osteosarcoma
}

National Cancer Institute

\section{Source}

National Cancer Institute. Metastatic Extraskeletal Osteosarcoma. NCI Thesaurus. Code C8808.

A soft tissue osteosarcoma which has spread to another anatomical site. 